\title{
Intention to use electronic medical record and its predictors among health care providers at referral hospitals, north-West Ethiopia, 2019: using unified theory of acceptance and use technology 2(UTAUT2) model
}

Mohammedjud Hassen Ahmed ${ }^{1 *}$ (D), Adina Demissie Bogale², Binyam Tilahun², Mulugeta Hayelom Kalayou², Jorn Klein ${ }^{3}$, Shegaw Anagaw Mengiste ${ }^{3}$ and Berhanu Fikadie Endehabtu ${ }^{2}$

\begin{abstract}
Background: Electronic Medical Records (EMRs) are systems to store patient information like medical histories, test results, and medications electronically. It helps to give quality service by improving data handling and communication in healthcare setting. EMR implementation in developing countries is increasing exponentially. But, only few of them are successfully implemented. Intention to use EMRs by health care provider is crucial for successful implementation and adoption of EMRs. However, intention of health care providers to use EMR in Ethiopia is unknown.

Objective: The aim of this study was to assess health care provider's intention to use and its predictors towards Electronic Medical Record systems at three referral hospitals in north-west, Ethiopia, 2019.

Methods: Institutional based cross-sectional explanatory study design was conducted from March to September among 420 health care providers working at three referral hospitals in north-west Ethiopia. Data were analyzed using structural equation model (SEM). Simple and multiple SEM were used to assess the determinants of health care providers intention to use EMRs. Critical ratio and standardized coefficients were used to measure the association of dependent and independent variables, 95\% confidence intervals and $P$-value were calculated to evaluate statistical significance. Qualitative data was analyzed using thematic analysis.

(Continued on next page)
\end{abstract}

\footnotetext{
* Correspondence: judhassen423@gmail.com

'Department of Health Informatics, Institute of Public Health, Mettu University, P.o.box: 196, Metu Zuria, Ethiopia

Full list of author information is available at the end of the article
}

(c) The Author(s). 2020 Open Access This article is licensed under a Creative Commons Attribution 4.0 International License, which permits use, sharing, adaptation, distribution and reproduction in any medium or format, as long as you give appropriate credit to the original author(s) and the source, provide a link to the Creative Commons licence, and indicate if changes were made. The images or other third party material in this article are included in the article's Creative Commons licence, unless indicated otherwise in a credit line to the material. If material is not included in the article's Creative Commons licence and your intended use is not permitted by statutory regulation or exceeds the permitted use, you will need to obtain permission directly from the copyright holder. To view a copy of this licence, visit http://creativecommons.org/licenses/by/4.0/ The Creative Commons Public Domain Dedication waiver (http://creativecommons.org/publicdomain/zero/1.0/) applies to the data made available in this article, unless otherwise stated in a credit line to the data. 


\begin{abstract}
(Continued from previous page)
Result: The mean age of the study subjects was 32.4 years \pm 8.3 SD. More than two-third 293(69.8\%) of the participants were male. Among 420 health care providers, only 167 (39.8\%) were scored above the mean of intention to use EMRs. Factors positively associated with intention to use EMRs were performance expectancy ( $\beta=$ $0.39, p<0.001)$, effort expectancy $(\beta=0.24, p<0.001)$, social influence $(\beta=0.18, p<0.001)$, facilitating condition $(\beta=$ $0.23, p<0.001)$, and computer literacy $(\beta=0.08, p<0.001)$. Performance expectancy was highly associated with intention to use EMRs.

Conclusion: Generally, about $40 \%$ of health care providers were scored above the mean of intention to use EMRs. Performance expectancy played a major role in determining health care providers' intention to use EMRs. The intention of health care providers to use EMRs was attributed by social influence, facilitating condition in the organization, effort expectancy, performance expectancy and computer literacy. Therefore, identifying necessary prerequisites before the actual implementation of EMRs will help to improve the implementation status.
\end{abstract}

Keywords: Electronic medical record system, Intention to use, UTAUT2model, Ethiopia

\section{Background}

In previous decades, healthcare sectors in many countries have experienced a number of changes due to advancement of information and communication technology (ICT) [1]. Health Information Technology (HIT) is a broad term that describes the technology and infrastructure used to record, analyze, and disseminate population health data [2, 3]. Integrating different information technologies (ITs) into the healthcare system of both developed and developing countries is not all about modernizing the health system but increase patient safety, improves communication, supports practicing evidence based decision and incorporating e-learning to remote health professionals. IT can used as a medium to access recent healthcare information, data handling and processing activities among health care providers [4]. Electronic Medical Records (EMRs) is a system that store patient information like medical histories, test results, and medications electronically [5]. The most significant contribution of EMR is that a patient will have one electronic chart that can be accessed any time with in one organization.

With the increasing demand for digital information in health care, the Electronic Medical Records (EMRs) represent the main foundation of health information technology in health care setting. Implementation of various technologies like EMRs contributes in improving health care organizations workflow. Utilization of EMRs are important for both patients and health care professionals to retrieve medical history, treatment results and previous diagnosis [6]. Poor health information system implementation has been identified as a major challenge in the health-care system in many developing countries including sub-Saharan African countries [7]. Correct and up-to-date information is critical for the provision of high-quality clinical care, for clinical and health service research, planning and management of health systems [8]. Paper based record system has limitations on accuracy, timeliness, completeness, consistency and legibility of hand writing. As EMRs) have been taken into use in the clinical field, the patients' data have become interoperable between different health care professionals in different service units and in different regions. The EMRs are expected to make a significant impact on health care data quality, healthcare outcomes and clinical practices [9-11].

Globally, many healthcare facilities tried to implement EMR system, mainly to improve health information recording process [12-16]. In the context of developing countries, several technological, organizational and social issues such as electrical power interruption, health professionals technology resistance, infrastructure and administrative problems have slowed the pace of implementation and adoption of EMRs [17]. Problems related to lack of planning, increased provider time, computer down time, lack of standards to interchange information, user resistance and threats to confidentiality negatively contribute for the successful implementation of EMR [4]. Even though there is a high expectation and interest in EMR as great prospect for improving quality, continuity, safety, and efficiency in healthcare, the overall adoption rate is relatively low $[18,19]$. Fifty percent of health information system failed to utilized EMRs properly [6, 20, 21].

Intention to use is a measurement to which a person has formulated conscious plans to perform or not to perform some specified future behavior for using EMRs [17]. EMRs intention to use by healthcare providers is an essential requirement to ensure that the expected benefits will be materialized and to predict the actual utilization of EMRs [22]. Evidences revealed that health professionals acceptance to the new system and the potential disruptions and changes that follow is one of the major barrier to implement EMR [23-25]. So, identifying the necessary prerequisites before the actual implementation of EMRs will help to improve the implementation status.

In Ethiopia, the ministry of health in collaboration with Tulane University developed a comprehensive EMR 
software system called Smart Care. The system had been deployed in Diredawa, Bahirdar, Harar and Addis Ababa city administrations of Ethiopia as a pilot, and the ministry of health had also planned to scale it up to other hospitals and regions [7]. In its pilot implementation phase, health professionals' resistance was reported to be the primary hindering factor to its successful adaptation. To the author's' knowledge, no study has been assessed intention to use EMRs among health care providers in Ethiopia. Therefore, this study aimed to determine intention of health care providers to use EMRs and associated determinants in selected referral hospitals in northwest Ethiopia.

\section{Theoretical model and hypotheses}

The most notable model has been introduced as 'Unified Theory of Acceptance and Use of Technology (UTAUT)' [26] to explain the relation of independent and dependent variable. This model was extracted from eight previous theoretical models that includes theory of reasoned action (TRA), Social Cognitive Theory (SCT), Technology Acceptance Model (TAM), Theory of Planned Behavior (TPB), Motivational model, Model of PC utilization (MPCU), Combined TAM and TPB (C-TAM-TPB) and Innovation Diffusion Theory (IDT) [26, 27]. In 2012,unified theory of acceptance and use of technology developed to predict acceptance and use of technology [27] has been introduced. The aim of this model was to connect Unified Theory of Acceptance and Use of Technology (UTAUT). Considering the three key structures, and changing some relations of the original concepts of UTAUT and introducing the new relationships is called the Unified Theory of Acceptance and Use of Technology2 (UTAUT2). Therefore, in addition to the four common variables (performance expectancy, effort expectancy, social influence and facilitating conditions) with UTAUT, three key variables of hedonic motivation, price value and habit were added to UTAUT2 model as independent variables. The following are Hypothesis $(\mathrm{H})$ of intention to use EMRs.

(H1): Performance expectancy will positively influence health care providers towards intention to use EMRs

(H2): Effort expectancy will positively influence health care providers towards intention to use EMRs

(H3): Social influence will positively influence health care providers towards intention to use EMRs (H4): Facilitating condition will positively influence health care providers towards intention to use EMRs (H5): Hedonic motivation will positively influence health care providers towards intention to use EMRs (H6): Habit will positively influence health care providers towards intention to use EMRs (H7): Computer literacy will have positively influence on health care provider's intention to use EMRs
This study considered seven independent constructs and one dependent construct. Price value was excluded from the study because of the study participants were not direct purchasers of the system. User behavior which was considered as dependent variable in the original UTAUT2 was not measured in this study due to the proposed technology is a predicted technology, which has not been implemented currently in Ethiopia and no current actual use of EMR in these three referral hospitals. The proposed model was not tested in Ethiopia context especially motivation, habit and computer literacy predictors. The effect of moderation on intention to use EMRs was not tested in previous studies. Finally, the proposed theoretical model is presented in Fig. 1.

\section{Methods}

\section{Study design and setting}

Institution based cross-sectional explanatory study design was conducted from March to September, 2019 at three referral hospitals in Amhara region, north-west Ethiopia. Amhara region consists of 10 administrative zones, one special zone and 78 urban centers. The regional health bureau is piloted EMRs in three pilot areas at Bahir-dar health center, Lalibela health center and Boru meda primary hospital. The region has planned to scale up to other facilities. This study was conducted at three selected referral hospitals namely; Felege-hiwot, University of Gondar, and Debre-Markos referral hospitals.

\section{Study participants and sample size determination}

In this study, health care providers working at three hospitals were taken as the study population.

The sample size was calculated using single population proportion formula with the following assumptions: $95 \%$ confidence level $(\mathrm{CI}), \mathrm{Z}(1-\alpha / 2)=1.96)$, an expected proportion of intention to use EMRs as 50, and 5\% margin of error. Considering a $10 \%$ non-response rate, the minimum final sample size was 423 . For the qualitative part; eleven study participants were participated and level of saturation used to determine the minimum sample size.

\section{Sampling procedure}

Study participants were selected using population proportion allocation from the three referral hospitals namely; university of Gondar, Felege-hiwot and Debre-markosl. Participant from each hospital were selected using simple random sampling technique. Purposive sampling method was used to select participants for the qualitative part.

\section{Data collection}

A structured self-administered questionnaire was prepared based on Unified Theory of Acceptance and Use technology2 (UTAUT2) [27, 28]. The questionnaire 


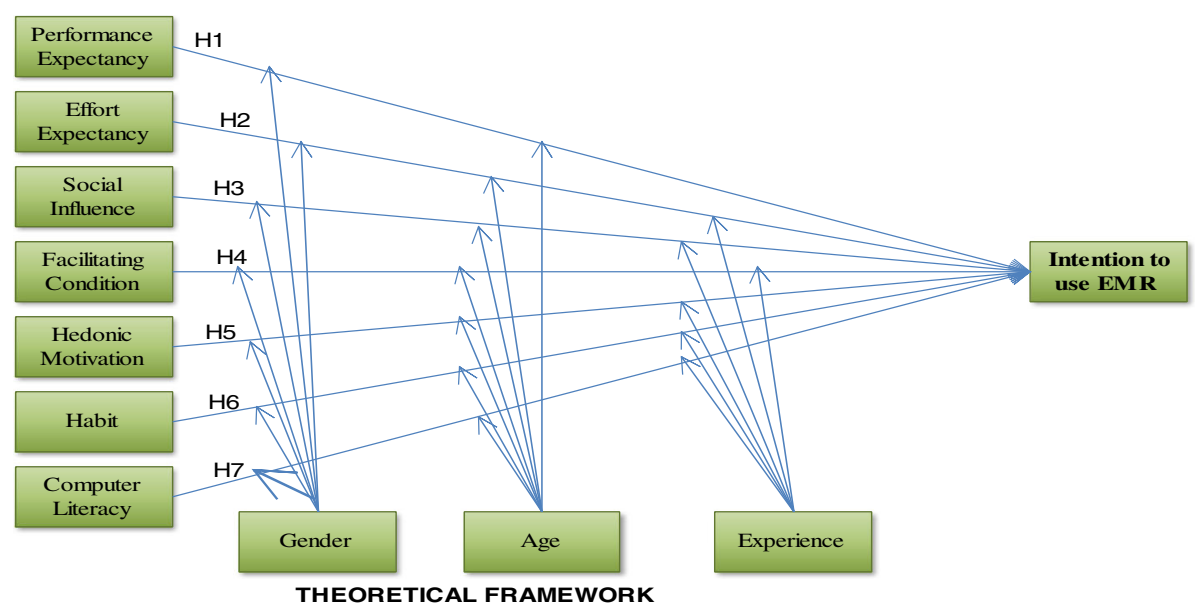

Fig. 1 Theoretical framework of Adopted UTAUT2 modeling

comprised of socio demographic and intention to use EMRs variables. It was prepared in English language. The tool was pre-tested on a group of 22 healthcare providers who did not belong to the study hospitals. Six data collectors and three supervisors participated in the data collection process. Two days training were given to the data collectors and supervisors on the objective of the study and data collection procedures. The principal investigator and supervisors did a daily supportive supervision on data collectors, and data back-up were performed to prevent data loss. For qualitative data, indepth interview was conducted and open ended questions were used. The minimum and maximum times for indepth interview were 34 and 47 min respectively.

\section{Study procedure}

Study participants were selected from three referral hospitals found in North-West, Ethiopia. Among the three referral hospitals from University of Gondar, Felege-hiwot and Debre-markos referral hospital, study participants for quantitative data were selected using population proportion allocation for each referral hospital. Simple random sampling technique was used to select study participants from the three referral hospital. Indepth interview was used for the qualitative part.

\section{Data management and analysis}

Epi-Info version 7 for data entry, and SPSS version 20 and AMOS version 23 were used to analyze data. Descriptive statistics was computed to describe socio demographic characteristics and univariate to assess magnitude of intention to use EMRs. Simple and multiple SEM analysis were carried out to identify the most important variables which could determine intention to use EMRs in the study areas. Chi-square, Goodness of Fit Index (GFI), Adjusted Goodness of Fit Index (AGFI),
Root Mean Square Error of Approximation (RMSEA) and Normal Fit Index (NFI) were used for checking fitness of the model. For the structural equation model, path coefficients were interpreted as SEM coefficients with the critical ratio calculated using bootstrapping. Similar to linear regression analysis, $R^{2}$ represents the proportion of variance in the endogenous constructs which can be explained by the predictors. Critical Ratio and standardized path coefficients were used to measure the association of dependent and independent variables, 95\% confidence intervals and $P$-value were used to evaluate statistical significance $(p$-value $<0.05)$. Qualitative data was analyzed using thematic analysis manually.

\section{Reliability and validity of the research}

Cronbach's alpha reliability coefficients were computed to determine the internal consistency of all research constructs: Cronbach's alpha of 0.7 or above indicates high reliability, between $0.5-0.7$ indicates moderate reliability and less than 0.5 indicates low reliability. Performance expectancy $(\alpha=0.70)$, effort expectancy $(\alpha=0.75)$, facilitating condition $(\alpha=0.69)$, computer literacy $(\alpha=0.77)$ and habit $(\alpha=0.80)$ were assessed by four Likert item questions and social influence $(\alpha=0.65)$, hedonic motivation $(\alpha=0.86)$ and intention to use EMRs $(\alpha=0.71)$ were assessed by three item questions (Table 1$)$.

\section{Results}

Out of the 423 questionnaires sent to the respondents, 420 were responded with a response rate of $99.30 \%$. The mean age of the study participants' was 32.4 years \pm 8.3 SD. More than two-third 293(69.8\%) of the participants were male. One third $141(33.6 \%)$ of the study participants were Nurses, $126(30.0 \%)$ were physicians and only $2(0.5 \%)$ were physiotherapist. About 185(44.0\%) of the study participants had less than 3 years working experience, and 
Table 1 Reliability of predictors and intention to use EMRs among health care providers in Northwest, Ethiopia

\begin{tabular}{llll}
\hline Construct & Sample size & Number of items & Cronbach's Alpha \\
\hline Performance Expectancy & 420 & 4 & 0.70 \\
Effort Expectancy & 420 & 4 & 0.75 \\
Social Influence & 420 & 3 & 0.65 \\
Facilitating Condition & 420 & 4 & 0.69 \\
Hedonic motivation & 420 & 3 & 0.86 \\
Computer Literacy & 420 & 4 & 0.77 \\
Habit & 420 & 4 & 0.80 \\
intention to use EMRs & 420 & 3 & 0.71 \\
\hline
\end{tabular}

only 60 (14.3\%) had more than 10 years working experience (Table 2).

Intention to use EMRs among health care providers was assessed by three Likert items having reliability test of Cronbach alpha $(\alpha=0.71)$. From "I intend to use EMRs system in the future" questions, Hundred sixty

Table 2 Socio-demographic characteristics of health care providers at three referral hospitals in north-west Ethiopia, 2019

\begin{tabular}{|c|c|c|}
\hline Variables & Frequency & Percent \\
\hline \multicolumn{3}{|l|}{ Gender } \\
\hline Male & 127 & $30.2 \%$ \\
\hline Female & 293 & $69.8 \%$ \\
\hline \multicolumn{3}{|l|}{ Age in years } \\
\hline $20-29$ & 233 & $55.5 \%$ \\
\hline $30-39$ & 91 & $21.7 \%$ \\
\hline $40-49$ & 72 & 17.1 \\
\hline $50-59$ & 24 & 5.7 \\
\hline \multicolumn{3}{|l|}{ Profession } \\
\hline Nurse & 141 & $33.6 \%$ \\
\hline Psychiatry & 7 & $1.7 \%$ \\
\hline Optometry & 8 & $1.9 \%$ \\
\hline Midwifery & 85 & $20.2 \%$ \\
\hline Physician & 126 & $30.0 \%$ \\
\hline Health officer & 4 & $1.0 \%$ \\
\hline Anesthesia & 7 & $1.7 \%$ \\
\hline Laboratory & 11 & $2.6 \%$ \\
\hline Radiology & 8 & $1.9 \%$ \\
\hline Physiotherapy & 2 & $0.5 \%$ \\
\hline Pharmacy & 16 & $3.8 \%$ \\
\hline Other & 5 & $1.2 \%$ \\
\hline \multicolumn{3}{|c|}{ Working experience in years } \\
\hline $1-3$ & 185 & $44.0 \%$ \\
\hline $3-5$ & 61 & $14.5 \%$ \\
\hline $5-10$ & 114 & $27.1 \%$ \\
\hline$>10$ & 60 & $14.3 \%$ \\
\hline
\end{tabular}

five of respondents (39.3\%) agree that they were intended to intention to use EMRs in the future (Table 3).

\section{Mean score of all predictors and intention to use EMRs in UTAUT2 model}

Performance expectancy, effort expectancy, facilitating condition, computer literacy and habit measured using four Likert item questions had a mean score of 14.1 $(\mathrm{SD} \pm 2.9), \quad 14.8(\mathrm{SD} \pm 2.9), \quad 13.3(\mathrm{SD} \pm 3.4), 12.4(\mathrm{SD} \pm 3.4)$ and $13.6(\mathrm{SD} \pm 3.7)$ respectively and social influence, hedonic motivation and intention to use EMRs also measured using three Likert questions and had a mean score of 11.0 ( $\mathrm{SD} \pm 2.2), 10.4(\mathrm{SD} \pm 3.4)$ and $10.1(\mathrm{SD} \pm$ 2.4) respectively.

\section{Magnitude of intention to use EMRs}

In this study, about 167(39.8\% [95.0\%: CI 35.0-45.0) of the study participants scored above the mean. The mean score of intention to use EMR was 10.1 with standard deviation of 2.4. The maximum and minimum scores were 15 and 3 respectively.

\section{Correlation analysis between predictors and intention to use EMRs}

There is positive correlation between performance expectancy (PE) $(r=0.83, p<0.001)$, facilitating condition (FC) $(r=0.76, p<0.001)$,effort expectancy (EE) $(r=0.73$, $p<0.001)$,social influence (SI) $(r=0.71, p<0.001)$ and computer literacy (CL) $(r=0.36, p<0.001)$ with intention to use EMRs among health care providers.

\section{Simple structural equation model analysis}

Figure 2 depicts the structural equation model showing path coefficients and $R^{2}$. The Bootstrap method was used to assess the statistical significance of the path coefficients of predictors. With respect to the key determinants of intention to use EMRs, performance expectancy has the most direct influence on intention to use EMRs, followed by effort expectancy, facilitating conditions, social influence and computer literacy. All 
Table 3 Intention to use EMRs among healthcare providers at three referral hospitals in northwest Ethiopia

\begin{tabular}{llllll}
\hline Items & Strongly disagree & Disagree & Neutral & Agree & Strongly agree \\
\hline I intend to use the EMRs system in the future & $10(2.4 \%)$ & $101(24.0 \%)$ & $96(22.9 \%)$ & $165(39.3 \%)$ & $48(11.4 \%)$ \\
I predict I will use the EMRs system in the future & $6(1.4 \%)$ & $90(21.4 \%)$ & $123(29.3 \%)$ & $159(37.9 \%)$ & $42(10.0 \%)$ \\
I plan to use the EMR system in the future & $5(1.2 \%)$ & $92(21.9 \%)$ & $108(25.7 \%)$ & $159(37.9 \%)$ & $56(13.3 \%)$ \\
\hline
\end{tabular}

values having $p$-value less than 0.2 in simple SEM were entered in to multiple SEM. Standardized coefficient and $\mathrm{R}^{2}$ values were used to interpret the effects and variability in the dependent variable respectively. The independent variables explained $83.0 \%$ of dependent variable. Significance independent predictors were discussed using 95.0\% Confidence Interval (CI) and $p$-value less than 0.05 was taken as a cut off point for association between independent variables and dependent variable.

As shown in Fig. 2, performance expectancy (the degree to which a user believes that EMR will improve performance) has a positive effect on intention to use EMR ( $\beta=$ $0.39, p<0.01)$. Similarly, the degree of ease of use, effort expectancy $(\mathrm{H} 2)$ associated with system use has a positive influence on intention to use EMR $(\beta=0.24 p<0.01)$. Social influence $(\mathrm{H} 3)$; the degree to which a user perceives the importance of others' opinion with respect to EMR use also plays a significant role in intention to use an $\operatorname{EMR}(\beta=0.18$ $p<0.01)$. The degree to which an individual believes that an organizational and technical infrastructure exists to support system use facilitating conditions (H4) is also significant with respect to intention to use EMRs $(\beta=0.23 p<0.01)$. Finally, computer literacy (H6) has a significant influence on intention to use EMRs $(\beta=0.08 p<0.01)$.
Hedonic motivation $(\mathrm{H} 5)(\beta=-0.01 p>0.05)$ and habit (H7) $(\beta=0.01 p>0.05)$ has no significance influence on intention to use EMRs. Overall, $83.0 \%$ of the variance with respect to intention to use EMRs was reasonably explained by the constructs of predictors (Table 4).

\section{Testing potential moderators: gender, age and experience}

In this section, possible moderations of the variables Gender, Age and Experience on the relationship of each of the significant independent variable (PE, EE, SI, FC and $\mathrm{CL}$ ) with the dependent variable (IU) were investigated. For each independent variable and for each potential moderator, two SEM were conducted. The first SEM includes the dependent variable on one of the independent variable (simple slopes). In the second SEM, both independent variable and an interaction term (independent variable * moderator) were added to AMOS to control for the moderator. If both the interaction term and significance difference between interaction term and independent variable of slopes were found to be significant (C.R difference between estimates of Moderator variable $>1.96$ or C.R $<-1.96)$ and $p$-value less than 0.05), then the proposed moderator variable was confirmed as a Moderator.

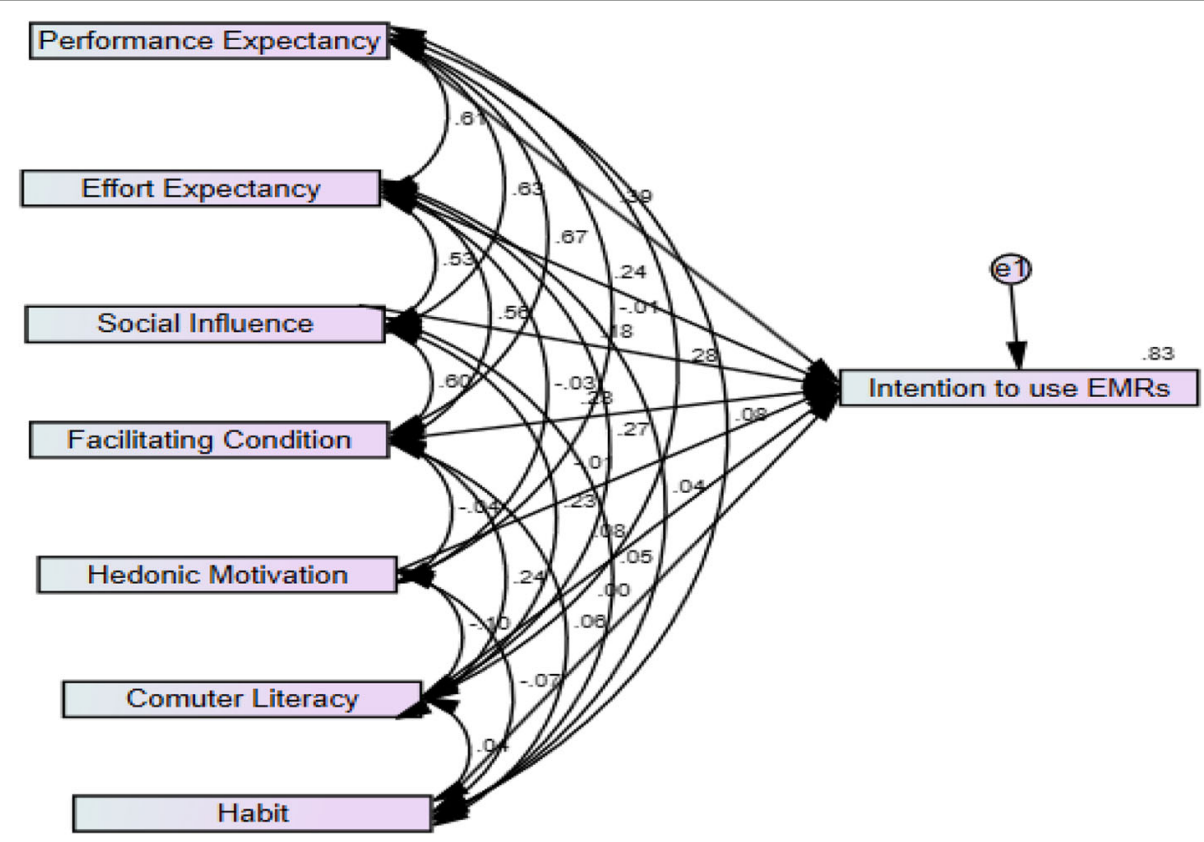

Fig. 2 Predictors and intention to use EMR among health care providers at referral hospitals North-west Ethiopia, 2019 
Table 4 Multiple Structural equations modeling association between predictors and intention to use EMRs among health care providers in Northwest, Ethiopia, 2019

\begin{tabular}{|c|c|c|c|c|c|c|c|c|}
\hline & & & \multirow[t]{2}{*}{ Estimate } & \multirow{2}{*}{$\begin{array}{l}\text { Standard } \\
\text { Error (SE) }\end{array}$} & \multirow{2}{*}{$\begin{array}{l}\text { Critical } \\
\text { Ratio (CR) }\end{array}$} & \multirow[t]{2}{*}{$P$} & \multicolumn{2}{|c|}{$95 \%$ confidence interval } \\
\hline & & & & & & & Lowerr & Upper \\
\hline PE & $\rightarrow$ & IU & 0.39 & 0.03 & 12.47 & * & 0.29 & 0.49 \\
\hline $\mathrm{EE}$ & $\rightarrow$ & IU & 0.24 & 0.02 & 9.04 & * & 0.17 & 0.33 \\
\hline SI & $\rightarrow$ & IU & 0.18 & 0.03 & 6.48 & * & 0.12 & 0.24 \\
\hline FC & $\rightarrow$ & IU & 0.23 & 0.02 & 7.90 & * & 0.16 & 0.30 \\
\hline HM & $\rightarrow$ & IU & -0.01 & 0.02 & -0.56 & 0.57 & -0.05 & 0.03 \\
\hline $\mathrm{CL}$ & $\rightarrow$ & IU & 0.08 & 0.02 & 3.96 & * & 0.03 & 0.13 \\
\hline $\mathrm{HB}$ & $\rightarrow$ & IU & 0.01 & 0.01 & 0.13 & 0.90 & -0.04 & 0.04 \\
\hline
\end{tabular}

Dependent variable: IU, * significance at $P<0.05$

Note: PE Performance expectance, EE Effort expectancy, SI Social Influence, FC Facilitating Condition, HM Hedonic Motivation, CL Computer Literacy, HB Habit, IU Intention to Use

Moderating effect of gender among health care providers on intention to use EMRs

As shown in the Table 5, there was no statistically significance difference between being male or female for all predictors on intention to use EMRs. The detail is presented in Table 5.

The relation between performance expectancy and intention to use EMRs is negatively moderated by Age $(\beta=-0.5, p=0.01)$ but other moderation variable of predictor's had no influence on intention to use EMRs. The detail is presented in Table 6 .

\section{SEM model fit and assumptions}

The table below (Table 7) presents the various SEM model fit indices (chi-square, GFI, AGFI, CFI, RMSEA and NFI) with their theoretical cut-offs. The 6 statistics values indicate that the SEM fit is fulfilled the assumption. SEM is based on a set of assumptions: The relationship between the dependent variable and each of the predictor should be linear (the expected value of the error terms is equal to zero); the error terms are normally distributed and errors have equal variances regardless of the values of the independent variables (homoscedastic assumption). Therefore, all fit indices support that the developed structural model fits well with the data. Based on the above information, the model passes SEM assumption.

\section{Result of qualitative data}

Exploring intention to use EMRs using qualitative method was used to find out barriers and challenges of using EMRs. Majority of the participants agreed that they are intended to use EMRs when necessary prerequisites to use EMRs full field in their organization like training and infrastructures as well as generator. One participant expressed his opinions about intention to use EMR in the following ways. "I am very eager to use EMR because it facilitates my tasks and easily to store and retrieve patient information using key words. So, I am looking forward to use it (EMRs)" 21-30 year's old. Another participant said "I am not that much good in computer skill but I have seen the important of EMRs for all parties

Table 5 Moderating effect of gender among health care providers at referral hospitals in north-west Ethiopia, 2019

\begin{tabular}{|c|c|c|c|c|c|}
\hline Variables & & Std. Coefficient & $C . R$ & P-value & $\begin{array}{l}\text { Critical Ratio difference between } \\
\text { Estimates of Gender }\end{array}$ \\
\hline \multirow[t]{2}{*}{ Performance Expectancy } & Female & 0.82 & 15.9 & * & $C . R=0.38$ and $p=0.71$ (Not Supported) \\
\hline & Male & 0.84 & 25.9 & * & \\
\hline \multirow[t]{2}{*}{ Effort Expectancy } & Female & 0.80 & 14.9 & * & C.R $=-1.6$ and $p=0.1$ (Not Supported) \\
\hline & Male & 0.70 & 16.9 & * & \\
\hline \multirow[t]{2}{*}{ Social influence } & Female & 0.71 & 11.5 & * & $C . R=-0.2$ and $p=0.96$ (Not Supported) \\
\hline & Male & 0.72 & 17.6 & * & \\
\hline \multirow[t]{2}{*}{ Facilitating Condition } & Female & 0.76 & 13.0 & * & $C . R=-1.5$ and $p=0.98$ (Not Supported) \\
\hline & Male & 0.76 & 19.9 & * & \\
\hline \multirow[t]{2}{*}{ Computer Literacy } & Female & 0.40 & 4.9 & * & $C . R=-0.6$ and $p=0.33$ (Not Supported) \\
\hline & Male & 0.34 & 6.1 & * & \\
\hline
\end{tabular}

Dependent variable: IU, * significance at $P<0.05$ 
Table 6 Moderating effect of age and experience among health care providers at referral hospitals in north-west Ethiopia, 2019

\begin{tabular}{|c|c|c|c|c|c|c|}
\hline Predictors & Interaction & Std. coefficient & $C \cdot R$ & $P$-value & $\begin{array}{l}\text { Significance difference } \mathrm{b} / \mathrm{n} \\
\text { interaction term with predictor }\end{array}$ & Confirmation \\
\hline Performance Expectancy (PE) & PE_X_Age & -0.50 & -2.8 & 0.01 & $\begin{array}{l}\text { Critical Ratio }=17.3 \\
\text { and } P=0.00^{*}\end{array}$ & Supported \\
\hline \multirow[t]{2}{*}{ Effort Expectancy (EE) } & EE_X_Age & -0.14 & -0.6 & 0.52 & & (Not Supported) \\
\hline & EE_X_Experience & -0.03 & -0.2 & 0.87 & & (Not Supported) \\
\hline \multirow[t]{2}{*}{ Social Influence (SI) } & SI_X_Age & -0.36 & -1.6 & 0.11 & & (Not Supported) \\
\hline & SI_X_Experience & -0.33 & -1.7 & 0.08 & & (Not Supported) \\
\hline \multirow[t]{2}{*}{ Facilitating Condition (FC) } & FC_X_Age & -0.27 & -1.5 & 0.14 & & (Not Supported) \\
\hline & FC_X_Experience & -0.15 & -1.1 & 0.26 & & (Not Supported) \\
\hline \multirow[t]{2}{*}{ Computer Literacy (CL) } & CL_X_Age & -0.11 & 0.4 & 0.69 & & (Not Supported) \\
\hline & CL_X_Experience & -0.08 & -0.4 & 0.70 & & (Not Supported) \\
\hline
\end{tabular}

Dependent variable: IU, ${ }^{*}$ significance at $P<0.05$

and if I get at least two more training days about it (EMRs),I will be definitely delighted to use in this hospital if implemented fully" 21-30 year's old.

Few of the participants raised their concerns regarding using EMRs and they were negatively intended to use EMRs in the future. Their concern is that it is not appropriate using computer in front of the patient. It will also create double burden to use both EMRs and paper based on health workers during power off. One participant said the following: "I will have double burden during power off when our hospital implements EMRs fully because I have to write in the paper and, when light is on, I will expect another task converting it (hard copy) into EMR which is disgusting if there is no generator" 21-30 year's old.

Generally, there were many factors that hindered intention to use of EMRs in selected referral hospitals. Shortage of financial incentives and priorities, poor electricity supply and internet connectivity, and primary user's limited computer skills were the hindering factors mentioned by participants. Financial supports and training of primary users were identified as facilitator to use EMRs. Majority of participants expected EMRs to improve their performance, easy to use and will have enough computer capacity about using EMRs in the future. Most participants were recommended that awareness needs to be given for those health care providers, who have negative intention towards using EMRs. For example one participant said "EMRs help health professional in different ways like it saves time to jot down notes, helps to see the drug adverse reaction for the patient in which it is difficult in today's system and generally promotes effectiveness and efficiency in health care industry" 31-40 year's old.

\section{Discussion}

This study examined to assess intention to use EMRs and to identify predictors among health care providers at referral hospitals in North-West Ethiopia using UTAUT2 model. Performance expectancy, effort expectancy, social influence, facilitating condition and computer literacy were predictors statistically associated with intention to use EMRs.

This study revealed that magnitude of intention to use EMRs was assessed by three Likert items with reliability test of Cronbach's alpha $(\alpha=0.71)$. In this study, about 167(39.8\% [95.0\%: CI 35.0-45.0) of the study participants scored above the mean. Score of intention to use EMRs. The mean score of intention to use EMRs was 10.1 with standard deviation of \pm 2.40 . The expected maximum and minimum score was 15 and 3 respectively.

Table 7 SEM fitness for intention to use EMRs among health care providers in north-west, Ethiopia, 2019

\begin{tabular}{lllll}
\hline Fit indices & Threshold & Authors & Results obtained & Conclusion \\
\hline Chi-square & $\leq 3$ & Balue & & Accepted \\
Goodness-of-fit-index (GFI) & $>0.9$ & Chau (1990). & 1.06 & Accepted \\
Adjusted goodness-of-fit-index (AGFI) & $>0.8$ & Chau (1997) & 0.98 & Accepted \\
Comparative fit index (CFI) & $>0.9$ & Bentler (1990) & 1.0 & Accepted \\
Root mean square error of approximation (RMSEA) & $<0.05$ & Byrne (2001) & 0.01 & Accepted \\
Normed fit index (NFI) & $>0.9$ & Bentler \& & 0.99 & Accepted \\
\hline
\end{tabular}


This study also identified predictors that influence intention to use EMRs. This study showed that performance expectancy played an important role in predicting health care providers intention to use EMRs $(\beta=0.39$, $p<0.001)$. This finding is supported by different literatures. A cross sectional study conducted in Ethiopia $(P<0.001)$ [29], South $\operatorname{Dakota}(\beta=0.27, p<0.01)$ [30], Indonesia $(\beta=0.30, p<0.05) \quad[31], \operatorname{Canada}(\beta=0.35, p<$ 0.001) [32], Taiwan $(\beta=0.29, p<0.001)$ [33], south Korea $(\beta=0.30, p<0.05)$ [34] and $\operatorname{Jordan}(\beta=0.39, p<0.01)$ [35]) positively influence intention to use EMRs among health care providers. This study revealed that EMR systems are directly related to improvements in the performances of healthcare providers. This might be due to People's intention to use EMRs in the work place are influenced by usefulness of EMRs for improving patient safety, and enhancing daily workflow [36].

This study also found that effort expectancy was statistically significant predictor of intention to use EMRs among health care providers $(\beta=0.24, p<0.001)$. This finding is in line with a study done in Ethiopia $(p<0.005)$ [29], Kenya $(\beta=0.18, p<0.001)$ [37] and comparative study done in US and Portugal $(\beta=0.16 ; P<0.01)[38]$, US $(\beta=$ $.187, p<.01)$ [39] positively influence intention to use EMRs. This might be due to individuals perception of users often want to be faced with a system that is easy to use provided that the system can meet the needs of their practical applications [40]. This might be also due to their perception that using EMRs will simplify their tasks and, information and data can also be managed in a clear and systematic way.

Another significance predictor of intention to use EMRs is social influence $(\beta=0.18, p<0.001)$. Social influence positively affects intention to use EMRs This result is consistent with a study done in morocco $(\mathrm{B}=$ 3.29, $p<0.001)$ [41], Taiwan $(\beta=0.16, p=0.015)$ [38], South Korea $(\beta=0.10, p<0.05)$ [34] and America $(\beta=$ $0.198 p<0.05)[42]$. Health care providers might perceive that external pressure towards using a new system could be possibly from the hospital administration, patients or health professionals [43]. So, healthcare staff members need to perceive pressure from external body, which is important for them to increase their motivation and intention to use EMRs in their organization. Mechanisms that encourage role modeling and peer support, such as champions and super users, might increase health care provider's acceptance of EMRs.

In this study, facilitating condition played an important role in predicting health care providers intention to use EMRs $(\beta=0.23, p<0.001)$. This is in line with a study conducted in North Central Nigeria $(\beta=0.11, p<$ 0.05) [44],South Africa $(\beta=0.28, p<0.05)$ [45],Malaysia $(\beta=0.16, p<0.05)[46]$ and Ontario Canada $(\beta=.11$, $p<.01$ ) [32]. It could be due to the fact that health care providers believe that the resources and technical support should be available to use the EMR in their workplace [43]. As training and organization readiness is the main part of facilitating condition, health care providers might also perceive that they will get favorable condition to use EMRs in the future if they take training.

Another significant predictor of the current study was computer literacy. Computer literacy was positively associated with intention to use EMRs $(\beta=0.08, p \leq 0.001)$. This finding is supported by a study conducted in Malaysia $(\beta=0.92 p \leq 0.01)[46]$, Taiwan $(\beta=0.14, p=$ 0.009) [47] and $\operatorname{Iran}(R=0.40, P<0.01)$ [1]. This might be due to that those who had computer literates believe that they will not face difficulty if EMRs system will be implemented in the future.

The finding of this study revealed that the influence of performance expectancy on health care provider's intention to use EMRs was negatively moderated by Age $(\beta=-0.5, p \leq 0.01)$. This finding is in line with other study conducted in China $(\beta=-0.33, p<0.001)$ [48]. A probable reason for this could be that older health care providers have less exposure for information technology. In contrast, due to their greater interaction with technologies growing up and in medical school, younger health care providers are more likely to feel more comfortable and able to adopt and use EMR system.

\section{Conclusion}

In conclusion, about $40 \%$ of health care providers were scored above the mean of intention to use EMRs. Factors associated with intention to use EMRs were performance expectancy, effort expectancy, social influence, facilitating condition and computer literacy influence intention to use EMRs. Among the five influencing factors, performance expectancy had more significant prediction power of intention to use EMRs than other predictor variables. The intention of health care providers to use EMRs was attributed by social influence, facilitating condition in the organization, effort expectancy, performance expectancy and computer literacy. Therefore, identifying necessary prerequisites before the actual implementation of EMRs will help to improve the implementation status.

\footnotetext{
Abbreviations

ADFI: Adjusted goodness of fit index; CFI: Comparative fit index; $\mathrm{Cl}$ : Confidence interval; CR: Critical ratio; EE: Effort expectancy;

EFMOH: Ethiopian federal ministry of health; E-HEALTH: Electronic health; EHR: Electronic health record; EMR: Electronic medical records; FC: Facilitating condition; GFI: Goodness of fit index; HIT: Health information technician; ICT: Information communication technology; IT: Information technology; IU: Intention to use; NFI: Normed fit index; NGO: Non-governmental organization; PE: Performance expectancy; RMSEA: Root mean square error of approximation; SD: Standard deviation; SEM: Structural equation modeling; SI: Social influence; SPSS: Statistical package for social science; TAM: Technology acceptance model; UTAUT: Unified theory of acceptance and use technology; WHO: World health organization
} 


\section{Acknowledgements}

The authors would like to thank University of Gondar institute of public health for the approval of ethical clearance, University of Gondar (DDCF project) financial support for data collection and hospitals, data collectors, supervisors and study participants.

\section{Authors' contributions}

All authors made substantial contributions to conception and design, acquisition of data, or analysis and interpretation of data; took part in drafting the article or revising it critically for important intellectual content; gave final approval of the version to be published; and agree to be accountable for all aspects of the work.

\section{Funding}

This study was supported by University of Gondar (DDCF project) for data collection. University of Gondar (DDCF project) has no any role in the design of the study, data collection, Analysis or interpretation of data, in the decisions on where, how or when to publish in the peer-reviewed press, or in preparation of the manuscript.

\section{Availability of data and materials}

The datasets generated and/or analyzed during the current study will be available upon reasonable request from the corresponding author.

\section{Ethics approval and consent to participate}

The study protocol was reviewed and approved by ethical review board of University of Gondar and written Informed consent was obtained from each study participant. Permission letter also obtained from Each Hospital. Names of participants and other personal identifiers were not included in the data collection tool.

\section{Consent for publication}

Not applicable.

\section{Competing interests}

The authors declare that we have no competing interests.

\section{Author details}

'Department of Health Informatics, Institute of Public Health, Mettu University, P.o.box: 196, Metu Zuria, Ethiopia. ${ }^{2}$ Department of Health Informatics, Institute of Public Health, University of Gondar, Gondar, Ethiopia. ${ }^{3}$ University of South-Eastern Norway, Post office box 235, N-3603 Kongsberg, Norway

Received: 23 January 2020 Accepted: 16 August 2020

Published online: 03 September 2020

\section{References}

1. Gagnon M, Kebir E, Kengne P, Simonyan D, Godin G, Labrecque M, et al. Electronic health record acceptance by physicians : testing an integrated theoretical model. J Biomed Inform. 2014;48:17-27.

2. Iqbal U, Ho C, Li YJ. The relationship between usage intention and adoption of electronic health records at primary care clinics. Comput Methods Prog Biomed. 2013;112(3):731-7.

3. Biruk K, Abetu E. Informatics in medicine unlocked modeling predictors of acceptance and use of electronic medical record system in a resource limited setting : using modi fi ed UTAUT model. Informatics Med Unlocked. 2019;17(April):100182.

4. Paré G, Raymond L, Ortiz A, Poba-nzaou P, Trudel M, Marsan J, et al. International journal of medical Informatics electronic health record usage behaviors in primary care medical practices : a survey of family physicians in Canada. Int J Med Inform. 2015;84(10):857-67.

5. Hsieh P-J, Lai H-M, Kuo P-Y. Physician Acceptance Behavior of the Electronic Medical Records Exchange: An extended decomposed theory of planned behavior medical records exchange: an extended. PACIS. 2013. p. 197.

6. Abdekhoda M, Ahmadi M, Dehnad A, Gohari M, Noruzi A. The effects of organizational contextual factors on physicians ' attitude toward adoption of electronic medical records. J Biomed Inform. 2014:(October):6-11.

7. Biruk S, Yilma T, Andualem M, Tilahun B. Health Professionals ' readiness to implement electronic medical record system at three hospitals in Ethiopia : a cross sectional study. BMC Med Inform Decis Mak. 2014;14:115.
8. Min-fang BT, Shin-yuan H, Wen-ju Y, Chen CC, C YD. Understanding Physicians ' Adoption Of Electronic Medical Records: Healthcare Technology Self-Efficacy, Service Level And Risk Perspectives. Comput Stand Interfaces. 2019:66:103342.

9. Bowman S. Impact of Electronic Health Record Systems on Information Integrity: Quality and Safety Implications. Perspect Heal Inf Manag. 2013. p. 10.

10. Schiff G, Hospital W, Bates DW, Hospital W. Can electronic clinical documentation help prevent diagnostic errors? 2010;(may 2014).

11. Velikova BG, Wright EP, Smith AB, Cull A, Gould A, Forman D, et al. Automated collection of Quality of life data: A comparision of paper and comupter Touch-screen Questionaries. J Clin Oncol. 1999;17(3):998-1007.

12. Lakew Y, Reda AA, Tamene H, Benedict S, Deribe K. Geographical variation and factors influencing modern contraceptive use among married women in Ethiopia : evidence from a national population based survey. Reprod Health. 2013;10(1):1.

13. Kupfer A, Schöb S, Ableitner L, Tiefenbeck V. Technology Adoption vs Continuous Usage Intention : do Decision Criteria Technology Adoption vs. Continuous Usage Intention : do Decision Criteria Change when Using a Technology ? 2016;(August).

14. Hennemann S, Beutel ME, Zwerenz R. Ready for eHealth ? Health professionals ' acceptance and adoption of eHealth interventions in inpatient routine care ready for eHealth ? Health professionals ' acceptance and adoption of eHealth interventions in inpatient routine care. J Health Commun. 2017;22(3):274-84.

15. Parvin R, Shahjahan M. Knowledge, Attitude, And Practice Of E-Health Among Doctors Working At Selected Private Hospitals in Dhaka, Bangladesh Rehana Parvin BPT, MPH, Md Shahjahan MCPS, MD. J Int Soc Telemed eHealth. 2016:4:e15:1-11. .

16. Liu $\mathrm{L}, \mathrm{Ma} \mathrm{Q}$. The impact of service level on the acceptance of application service oriented medical records. Inf Manag. 2005;42:1121-35.

17. Ahlan AR, Isma B. User acceptance of Health information technology ( HIT ) in developing countries : a conceptual model. Procedia Technol [Internet]. 2014;16:1287-96 Available from: https://doi.org/10.1016/j. protcy.2014.10.145.

18. Chebole GC, Submitted R, Partial IN, The FOR, For R, Award THE, et al. Factors influencing adoption of electronic medical record systems in public health facilities in Kenya: a CASE of NAKURU county. 2015.

19. Tessema GA, Megabiaw B, Tadesse Z, Ayele A. Birth interval and its predictors among married women in Dabat District, Northwest Ethiopia : A retrospective follow up study Birth interval and its predictors among married women in Dabat District, Northwest Ethiopia : A retrospective follow up study B. 2013;(February 2015).

20. Villalba-mora E, Casas I, Lupia F. Adoption of health information technologies by physicians for clinical practice: The Andalusian. Int J Med Inform. 2015. p. 1-9.

21. Hung S, Yu W, Tsai M, Yen DC. What Drives Physicians ' Intention to Use Electronic Medical Record System : The Roles of Perceived Service Level, Computer Self-Efficacy, and Perceived Risk ELECTRONIC MEDICAL RECORD SYSTEM : THE ROLES OF. 2013;

22. Kuo K, Liu C, Ma C. An investigation of the effect of nurses' technology readiness on the acceptance of mobile electronic medical record systems. BMC Med Inform Decis Mak. 2013:(8):1-14.

23. Al-aswad AM, Brownsell S, Palmer R, Nichol JP. A Review Paper of the Current Status of Electronic Health Records Adoption Worldwide: The Gap between Developed and Developing Countries. J Health Inform Dev Ctries. 2013;7(2):153-64.

24. Boonstra A, Broekhuis M. Barriers to the acceptance of electronic medical records by physicians from systematic review to taxonomy and interventions. 2010:

25. Shiells K, Holmerova I, Steffl M, Stepankova O, Shiells K, Steffl M. Electronic patient records as a tool to facilitate care provision in nursing homes : an integrative review nursing homes : an integrative review. Informatics Heal Soc Care. 2018;00(00):1-16.

26. Morris MG, Hall M, Davis GB, Davis FD, Walton SM. U SER A CCEPTANCE OF I NFORMATION T ECHNOLOGY : T OWARD A U NIFIED V IEW 1. 2003;27(3):425-78.

27. Venkatesh $V$, Thong JY, Xu X. Consumer acceptance and use of information technology: extending the unified theory of acceptance and use of technology. MIS Q. 2012;36(1):157-78.

28. Ahlan AR. An overview of patient acceptance of Health Information Technology in developing countries: a review and conceptual model. Int J Inf Syst Proj Manag. 2015;3(1):29-48. 
29. Biruk K, Abetu E. Modeling predictors of acceptance and use of electronic medical record system in a resource limited setting: using modified UTAUT model. Informatics Med Unlocked. 2019;17:100182.

30. Wills MJ. Examining healthcare professionals' acceptance of electronic medical records using UTAUT. Issues Inf Syst. 2008;9(2):396-401.

31. Arman AA. Development of user acceptance model for electronic medical record system. 2015;

32. Cocosila M. A Blended Model of Electronic Medical Record. 2016;39.

33. Hung S, Yu W, Tsai M, Yen DC. What Drives Physicians ' Intention to Use Electronic Medical Record System: The Roles of Perceived Service Level, Computer Self-Efficacy, and Perceived Risk of Electronic Medical Record System: PACIS. 2013. p. 194

34. Venugopal P, Jinka S, Priya SA. User Acceptance of Electronic Health Records: Cross Validation of Utaut Model. Glob Manag Rev. 2016;10(3):4254.

35. Tubaishat A. Perceived usefulness and perceived ease of use of electronic health records among nurses: Application of Technology Acceptance Model Perceived usefulness and perceived ease of use of electronic health records among nurses: Application of Technology Acce. 2018.

36. Tubaishat A. Perceived usefulness and perceived ease of use of electronic health records among nurses: Application of Technology Acceptance Model Perceived usefulness and perceived ease of use of electronic health records among nurses : Application of Technology Acce. 2018;(September 2017).

37. Amulega VO. UNIVERSITY OF NAIROBI SCHOOL OF COMPUTING \& INFORMATICS determinants of use of electronic medical records systems to deliver. 2018:

38. Kim $\mathrm{S}$, Lee $\mathrm{K}$, Hwang $\mathrm{H}, \mathrm{Yoo} \mathrm{S}$. Analysis of the factors influencing healthcare professionals' adoption of mobile electronic medical record ( EMR ) using the unified theory of acceptance and use of technology ( UTAUT ) in a tertiary hospital. BMC Med Inform Decis Mak. 2016;16:1-12.

39. Ouattara A. Antecedents of employees ' Behavioral intentions regarding information technology Consumerization. 2017:

40. Garavand A, Mohseni M, Asadi H, Etemadi M, Moradi-joo M, Services H, et al. Electronic Physician ( ISSN : 2008-5842 ). 2016;(August):2713-8,

41. Bennani A, Oumlil R. IT Acceptance by Nurses in Morocco : Application of a Modified Unified Theory of Acceptance and Use of Technology 2014;2014.

42. Tavares J. Electronic Health Record Portal Adoption : a cross country analysis. 2017;1-17.

43. Jeyakodi T. Acceptance and Use of Electronic Medical Records in Sri Lanka. 2016;V $V(\mid): 1-5$.

44. Idoga PE, Toycan M, Nadiri H, Çelebi E. Assessing factors militating against the acceptance and successful implementation of a cloud based health center from the healthcare professionals' perspective: a survey of hospitals in Benue state, northcentral Nigeria. BMC Med Inform Decis Mak. 2019;19:34.

45. Cohen JF, Bancilhon J, Jones M. South African physicians ' acceptance of eprescribing technol- ogy : an empirical test of a modified UTAUT model 2013;(50):43-54

46. Mukred M, Yusof ZM, Alotaibi FM, Mokhtar UMIA, Fauzi F. The key factors in adopting an electronic records management system (ERMS) in the educational sector : a UTAUT-based framework. IEEE Access. 2019;7:35963-80.

47. Huang W-M, Chen T, Hsieh C-W. An Empirical Study on The Physicians' Behavioral Intention With Electronic Medical Record Systems In Taiwan. PACIS. 2014. p. 160.

48. Venkatesh V, Sykes TA. ' Just W hat the Doctor Ordered ': A Revised UTAUT for EMR System Adoption and Use by Doctors $U$ nified T heory of $U$ se of T echnology Contextualizing to Doctor 's EMR s ystem a doption and u se. 2011;1-10.

\section{Publisher's Note}

Springer Nature remains neutral with regard to jurisdictional claims in published maps and institutional affiliations.

Ready to submit your research? Choose BMC and benefit from:

- fast, convenient online submission

- thorough peer review by experienced researchers in your field

- rapid publication on acceptance

- support for research data, including large and complex data types

- gold Open Access which fosters wider collaboration and increased citations

- maximum visibility for your research: over $100 \mathrm{M}$ website views per year

At BMC, research is always in progress.

Learn more biomedcentral.com/submissions 